References

Dreiling, D. A. (1970). The early diagnosis of pancreatic cancer: quadrenial Scand. J. Gastroent., 5, Suppl. 6, 115.

Dreiling, D. A. (1955). The technique of the secretin test. J. Mnt Sinai Hosp., 21, 363-372.

Dreiling, D. A. (1971). Investigation of pancreatic function. In The Exocrine Pancreas, edited by I. T. Beck, and D. G. Sinclair pp. 154-166. Churchill, London.

Dreiling, D. A. (1972). Pancreatic function in patients with ZollingerEllison syndrome. Amer. J. Gastroent., 58, 66-72.

Dreiling, D. A., and Bordalo, O. (1973). Secretory patterns in minimal pancreatic pathologies. Amer. J. Gastroent., 60, 60-69.

Dreiling, D. A., Greenstein, A. J., and Bordalo, O. (1975). The augmented test of pancreatic secretion: tubular cell mass and secretory capacity. Amer. J. Gastroent., in press.

Dreiling, D. A., Greenstein, A. J., and Bordalo, O. (1975). The hypersecretory states of the pancreas. Amer. J. Gastroent., 59, 505.

\section{The Lundh test in the diagnosis of pancreatic disease: A comment from the Moderator}

\section{SHEILA L. WALLER From the MRC Gastro- enterology Unit, Central Middlesex Hospital, London}

Dr Dreiling's excellent account of the value of the secretin test for the diagnosis of abnormal pancreatic function is based on a large experience gained over many years. Many workers, however, find the secretin test impracticable and the results difficult to interpret. The busy clinician needs a simple test of pancreatic function with a reasonable diagnostic success rate. Our experience, based on data from nearly 1000 patients, suggests that the Lundh test of pancreatic exocrine function (Lundh, 1962) fulfils these criteria. Moreover it is physiological and inexpensive in terms of resources (Cook, LennardJones, Sherif, and Wiggins, 1967; Mottaleb, Kapp, Noguera, Kellock, Wiggins, and Waller, 1973). Other workers have reported similarly (Levin, Youngs, and Bouchier, 1972; Zeitlin and Sircus, 1974).

Estimation of exocrine function by any method has a limited diagnostic value because the range of normal is wide and very extensive pancreatic damage or duct obstruction must be present before pancreatic function is markedly diminished. Severe focal pancreatic destruction may be present without alteration of exocrine secretion; patients with nongastrointestinal disorders may have abnormally low pancreatic function. The Lundh test is frequently criticized on the grounds that it is not a function test in physiological terms because the pancreas is stimulated indirectly. It is therefore important to determine whether under clinical conditions this procedure is as useful as the secretin test in the diagnosis of pancreatic disease. Preliminary comparisons have suggested that it is (Waller, Kapp,
Dreiling, D. A., Greenstein, A., and Bordalo, O. (1973b). Newer concepts of pancreatic secretory patterns: pancreatic secretory mass and capacity. Mnt Sinai J. Med., 40, 666-676.

Dreiling, D. A., and Hollander, F. (1948). Studies in pancreatic function. I. Preliminary series of clinical studies with the secretin test. Gastroenterology, 11, 714-729.

Dreiling, D. A., and Janowitz, H. D. (1962). The measurement of pancreatic secretory function. In Ciba Foundation Symposium, on The Exocrine Pancreas: edited by A. U. S. de Reuck and M. P. Cameron, pp. 225-253. Churchill, London.

Dreiling, D. A., Janowitz, H. D., and Perrier, C. (1964). The diagnosis of pancreatic disease. In Pancreatic Inflammatory Disease, pp. 129-147. Hoeber, Harper and Row, New York.

Tiscornia, O., and Dreiling, D. A. (1966). Recovery of pancreatic exocrine secretory capacity following prolonged ductal obstruction. Ann. Surg., 164, 267-270.

Tiscornia, O., and Dreiling, D. A. (1966). Does the pancreatic gland regenerate? Gastroenterology, 51, 267.

Noguera, Kellock, and Wiggins, 1972; Lurie, Brom, Bank, Novis, and Marks, 1973). We have now extended our comparison of the two tests. Twenty patients with non-gastrointestinal disorders acted as controls. These patients and 21 patients with pancreatic disease proven by means other than a function test had both a Lundh and a secretin test. The Lundh test was performed as described previously (Cook et al, 1967; Mottaleb et al, 1973). For the secretin test, Jorpes secretin was given by intravenous infusion for two 40-minute periods at doses of 1 and 2 clinical units $/ \mathrm{kg} / \mathrm{hour}$. Ten-minute collections of duodenal juice were made throughout the test. Limits of normal were calculated for the following variables from the data on controls: the maximum bicarbonate concentration/10-minute period, the maximum bicarbonate output $/ \mathrm{kg} / 30$ minutes, and the maximum volume secreted $/ \mathrm{kg} / \mathrm{half}$ hour. The latter two variables were calculated from the three consecutive 10-minute collections during the 80

\begin{tabular}{lll}
\hline & $\begin{array}{l}\text { Chronic } \\
\text { Pancreatitis }\end{array}$ & $\begin{array}{l}\text { Pancreatic } \\
\text { Carcinoma }\end{array}$ \\
\hline No. of patients & 13 & 8 \\
Lundh successful & 13 & 8 \\
Secretin successful & 13 & 6 \\
Lundh abnormal & 9 & 7 \\
Secretin abnormal & 8 & 5 \\
\hline
\end{tabular}

Table I Comparison of Lundh and secretin tests

\begin{tabular}{lll}
\hline & $\begin{array}{l}\text { Chronic } \\
\text { Pancreatitis }\end{array}$ & $\begin{array}{l}\text { Pancreatic } \\
\text { Carcinoma }\end{array}$ \\
\hline $\left.\begin{array}{l}\text { Lundh abnormal } \\
\text { Secretin normal }\end{array}\right\}$ & 1 & 1 \\
$\left.\begin{array}{l}\text { Lundh normal } \\
\left.\begin{array}{l}\text { Secretin abnormal } \\
\text { Lundh suggests carcinoma }\end{array}\right\}\end{array}\right\}$ \\
$\begin{array}{l}\text { Secretin no lead } \\
\left.\begin{array}{l}\text { Lundh no lead } \\
\text { Secretin suggests carcinoma }\end{array}\right\}\end{array}$ & 0 & 1 \\
\hline
\end{tabular}

Table II Lundh and secretin tests in the differential diagnosis of chronic pancreatitis and pancreatic carcinoma 
minutes that gave the maximal result. The secretin test was considered abnormal if any one of these variables fell below the lower limits for control subjects.

There was little difference between the two tests (table I) and neither test was better than the other in the separation of chronic pancreatitis from pancreatic carcinoma (table II).

The results suggest that the Lundh test is likely to be more useful in clinical practice because of its practical advantages. The secretin test could be reserved for more complicated cases, eg, for some patients with coeliac disease.

References

Cook, H. B., Lennard-Jones, J. E., Sherif, S. M., and Wiggins, H. S.
(1967). Measurement of tryptic activity in intestinal juice as a diagnostic test of pancreatic disease. Gut, 8, 408-414.

Levin, G. E., Youngs, G. R., and Bouchier, I. A. D. (1972). Evaluation of the Lundh test in the diagnosis of pancreatic disease. J. clin. Path., 25, 129-132.

Lundh, G. (1962). Pancreatic exocrine function in neoplastic and inflammatory disease; a simple and reliable new test. Gastroenterology, 42, 275-280.

Lurie, B., Brom, B., Bank, S., Novis, B., and Marks, I. N. (1973). Comparative response of exocrine pancreatic secretion following a test meal and secretin-pancreozymin stimulation. Scand. J. Gastroent., 8, 27-32.

Mottalob, A., Kapp, F., Noguera, E. C. A., Kellock, T. D., Wiggins, H. S., and Waller, S. L. (1973). The Lundh test in the diagnosis of pancreatic disease: A review of five years' experience. Gut $14,835-841$.

Waller, Sheila L., Kapp, F., Mottaleb, A., Noguera, E. C. A., Kellock, T. D., and Wiggins, H. S. (1972). A preliminary comparison of the Lundh and secretin pancreozymin tests in the diagnosis of pancreatic disease. (Abstr.) Arch. Mal. Appar. dig., 61, 227C.

Zeitlin, I. J., and Sircus, W. (1974). Factors influencing duodenal trypsin levels following a standard test meal as a test of pancreatic function. Gut, 15, 173-179.

\section{Endoscopic retrograde choledochopancreatography in the diagnosis of pancreatic disease}

\section{P. R. SALMON}

\section{From Bristol Royal Infirmary}

The diagnosis of pancreatic disease remains difficult in spite of the recent advances afforded by fibreoptic endoscopy. The introduction of fibre-optic endoscopy (Hirschowitz, Curtiss, Peters, and Pollard 1958) and the subsequent development of a cannulating endoscope (Takagi, Go, Sugiura, Futagawa, and Hioki, 1969; Oi, Ichioka, and Takemoto, 1969; Oi, 1970; Takagi, Ikeda, Nakayama et al, 1970) have led to the widespread use of endoscopic retrograde choledochopancreatography (ERCP) in the diagnosis and management of pancreatic and biliary tract disease (Oi, 1970; Oi, Takemoto, and Nakayama, 1970; Oi, Kobayashi, and Kono, 1970; Takagi et al, 1970; Ogoshi, Tobita, and Hara, 1970; Fujita, Soma, and Kidokoro, 1970; Demling and Classen, 1970; Kasugai, Kuno, Aoki et al, 1971; Kobayashi, Tanaka, and Tsuneoka, 1971; Salmon, Brown, Htut, Burwood, and Read, 1971a; Cotton, Salmon, Blumgart, Burwood, Davies, Lawrie, Pierce, and Read, 1972; Blumgart, Salmon, Cotton, Davies, Burwood, Beales, Lawrie, Skirving, and Read, 1972; Kasugai, Kuno, Kobayashi, and Hattori, 1972; Burwood, Davies, Lawrie, Blumgart, and Salmon, 1973; Blumgart, Salmon, and Cotton, 1974). Clinically ERCP is of value both in suspected and in known pancreatic disease. It can provide simul- taneous information from both the biliary tract and the pancreas and therefore detect primary biliary tract disease and biliary complications of pancreatic disease. In addition, a more precise definition of pancreatic pathology is possible leading to the detection of complications such as pancreatic duct strictures, cysts, and calculi. Finally, additional procedures may be provided (the collection of pancreatic juice and cytology) or be indicated (eg, percutaneous transhepatic cholangiography, selective pancreatic angiography). These indications are set out in table I.

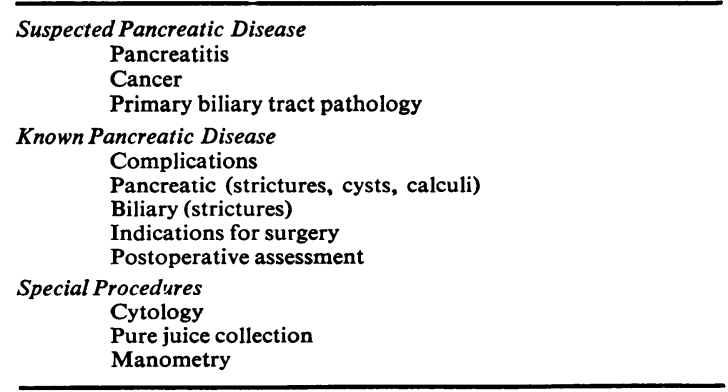

Table I Indications for ERCP in pancreatic disease 